\title{
Panfacial bone fracture: cephalic to caudal
}

\section{Seonsik Yun, Youngcheon $\mathrm{Na}$}

Department of Plastic and Reconstructive Surgery, Wonkwang University Hospital, Wonkwang University School of Medicine, Iksan, Korea
Theoretically, panfacial bone fractures involve all three areas of the face: frontal bone, midface, and mandible. In practice, when two out of these three areas are involved, the term "panfacial bone fracture" has been applied. We can use physical examination, simple radiologic examination, and computed tomography study for diagnosis. Linear fracture are treated by conservative treatment. But, most of panfacial bone fracture patients need to be treated by open reduction and internal fixation. Facial width is most important thing that we need to care during operation. There are many ways about sequence like "top to bottom," "bottom to top," "outside to inside," or "inside to outside" and the authors prefer "top to bottom" and "outside to inside" ways. The authors apply arch bar from the first of surgery and then, set frontal bone fracture, midface fracture and mandible fracture in sequence. Usually, we remove the stitches for 5 days after surgery and the intraoral stitch removed after 2 weeks. Usually arch bar is going to be removed 4 weeks after surgery. We could get acceptable results with the above way.

Keywords: Bone fracture / Cephalic / Caudal

\section{INTRODUCTION}

High velocity accidents may create profound injury to the bones of skull and face. These injuries, craniofacial in the true sense of the word, are a challenge to even the most energetic and welltrained reconstructive surgeons [1]. Conceptually, panfacial bone fractures involve all three areas of the face: frontal bone, midface, and mandible. In practice, when two out of these three areas are involved, the term "panfacial bone fracture" has been applied [2].

Since 1980's as CT study developed, diagnosis of fracture took a great leap forward [3]. Treatment of fracture evolved passing through World War II. Technical advances of reduction made therapeutic principles change a bit, from "closed reduction with external fixation," "wiring" to "internal fixation with screw fixation." "Bottom to top," setting mandible bone, frontal bone, midface in sequence, was the general tendency in the past [4]. Nowadays, "top to bottom" becomes choosable as technique of

\section{Correspondence: Youngcheon $\mathrm{Na}$}

Department of Plastic and Reconstructive Surgery, Wonkwang University Hospital, Wonkwang University School of Medicine, 895 Muwang-ro, Iksan 54538, Korea

E-mail: ycnadr@hanmail.net

Received September 7, 2016 / Revised February 27, 2018 / Accepted February 27, 2018 reduction developed. There are "outside to inside," "inside to outside" ways, depending on which part of bone would be set first. We prefer the top to bottom and outside to inside ways.

\section{TREATMENT}

First of all, we need to check patient's general condition, when there is panfacial bone fracture through physical examination or radiologic study. It is ideal to have surgery or treatment as soon as possible, but most of patient are going to take life-supporting treatment in advance, due to injury of central nervous system or other organs. Thus, it takes 2-3 weeks to have surgery, generally. Surgery is performed after completely peeling off the fracture site through many kinds of incisions; the coronal incision, lower eyelid incision, the mandibular and maxillary gingival-buccal-sulcus incisions, and preauricular-retromandibular incision [5].

Applying an arch bar goes first to make occlusion right. Because occlusion is one of the most important purposes of surgery of panfacial bone fracture. Through the incisions mentioned above, make sure of the fracture site. Set frontal bone and midface. When setting midface, adjust facial width first by setting zygo- 
matic body and zygomatic arch. And then, set nasoorbitoethmoid fracture which is inside fracture site.

After finishing reduction of midface, reduction of mandibular fracture should be performed. Finally perform proper treatment if there is soft tissue injury. We usually check out X-ray if reduction is properly performed, right after surgery. The stitches will be removed after 5 days since surgery and removal of intraoral stitches will be done after 2 weeks with follow-up X-ray. Let the patient avoid wearing spectacles or external forces. If there is no specific reason, we usually remove the arch bar after 4 weeks. Let the patient do mouth opening exercise one time in a week if arch bar is continuously fixated with rubber. After removing, let the patient open mouth properly checking occlusion with mirror until open his mouth naturally.

\section{CONCLUSION}

It is important to make sure of buttress articulation when performing open reduction and internal fixation. Because buttress articulation makes alignment set and fixation easy, consequently anatomic reduction is possible [6]. Applying an arch bar goes first, to make occlusion right. Because occlusion is one of the most important purposes of surgery of panfacial bone fracture including cosmetic purpose. And then, we choose between "top to bottom" and "bottom to top."

For occlusion, setting a mandibular fracture is preferred because it is hard to set tightly using external fixation or wiring in the past. But with a screw fixation, it is possible to set tightly nowadays. So, we would get good results by "top to bottom" applying arch bar for occlusion. Mostly the author uses screw fixation and midface reduction is much more familiar. So, we prefers "top to bottom."

Facial dimensions like width, projection and height are needed to be considered and facial width is most important item [4]. Because differences of width are much easier to recognize comparing height and projection. Differences in height and projection are rare and less recognizable. When performing reduction with "inside to outside" technique, it is easy to miss gap caused by bone loss and asymmetry of facial width could occur due to insufficient reduction. On the other hand, with "outside to inside" technique, it is easy to set symmetry of facial width by setting zygomatic body and zygomatic arch first. It could make enough space for NEO fracture which is collapsed or severely fragmented and also easy to decide about bone graft by checking gap caused by bone loss. So, this is why the author prefer "outside to inside" technique and he got acceptable results in most of cases.

Panfacial bone fracture could lead to many kinds of complication like enophthalmos, malocclusion, facial width asymmetry, diastasis, ectropion, fat atrophy. It is hard to reconstruct completely when there is severe injury. So, it let down patient, doctor both. But, we could expect best results if there is the best treatment for patient considering accurate anatomical knowledge and situation.

\section{CONFLICT OF INTEREST}

No potential conflict of interest relevant to this article was reported.

\section{REFERENCES}

1. Gruss JS, Pollock RA, Phillips JH, Antonyshyn O. Combined injuries of the cranium and face. Br J Plast Surg 1989;42:385-98.

2. Neligan PC, Song DH. Plastic surgery. Vol. 4. lower extremity, trunk and burns. Philadelphia: Mosby Elsevier; 2013.

3. Kassel EE, Noyek AM, Cooper PW. CT in facial trauma. J Otolaryngol 1983;12:2-15.

4. Kelly KJ, Manson PN, Vander Kolk CA, Markowitz BL, Dunham $\mathrm{CM}$, Rumley TO, et al. Sequencing LeFort fracture treatment (organization of treatment for a panfacial fracture). J Craniofac Surg 1990;1:168-78.

5. Manson PN, Clark N, Robertson B, Crawley WA. Comprehensive management of pan-facial fractures. J Craniomaxillofac Trauma 1995;1:43-56

6. Gruss JS, Mackinnon SE. Complex maxillary fractures: role of buttress reconstruction and immediate bone grafts. Plast Reconstr Surg $1986 ; 78: 9-22$ 